\title{
A demonstration of the cessation of spontaneous combustion in a coal overburden spoil pile
}

\author{
A Garvie SRK Consulting (Australasia) Pty Ltd, Australia \\ K Donaldson Flinders Power, Australia \\ B Williams Flinders Power, Australia \\ J Chapman SRK Consulting (Australasia) Pty Ltd, Australia
}

\begin{abstract}
Leigh Creek Coal Mine is located in South Australia approximately $550 \mathrm{~km}$ north of Adelaide and operated between 1944 and 2015. During operations, localised spontaneous combustion occurred on numerous occasions in the overburden spoil piles containing relatively small volumes of coal (about $0.8 \%$ ). The majority of the overburden sequence consisted of sandstones and carbonaceous mudstones. Samples of overburden rocks had total sulfur and total organic carbon present at up to 2.2 and $14 \mathrm{wt} \%$ respectively. At the end of mining, localised surface temperatures of up to $200^{\circ} \mathrm{C}$ were measured.

Laboratory testing demonstrated the potential for self-heating and spontaneous combustion of both coal and overburden material in the spoil piles. The management strategy selected for preventing spontaneous combustion in the post-closure period included:

- Reducing the batter angle of the spoil pile to within the range of 1:4.5 to 1:5.0 (V:H).

- Covering with a compacted layer of fine-grained inert material.
\end{abstract}

A trial of the management strategy was established in June 2017 in a location that was actively combusting. The batter slopes of the area were reduced, and an inert cover was placed over the area. Measurements of temperature, oxygen and carbon dioxide concentrations in the spoil pile over 20 months show that:

- Most oxygen is consumed within the top $1 \mathrm{~m}$ of spoil.

- Carbon dioxide concentrations have decreased and are consistent with historical combustion and ongoing oxidation of the carbonaceous mudstone.

- Overall, a net heat loss from the spoil pile has occurred as indicated by decreasing temperatures.

- Temperatures have decreased below the threshold required for the initiation of spontaneous combustion.

Spoil pile conditions before and after the implementation of the management strategy are presented and an assessment of the effectiveness of the management strategy is provided.

Keywords: spontaneous combustion, overburden spoil pile, temperature, gas concentration, permeability, mitigation strategy, closure

\section{$1 \quad$ Introduction}

The Alinta Energy Board announced the closure of the Leigh Creek Coal Mine in June 2015; consequently, coal mining operations ceased in November 2015. A risk mapping process undertaken by the operator, Flinders Power, and the South Australian mining regulators identified future risks associated with uncontrolled spontaneous combustion. In particular, spontaneous combustion occurrences in the waste spoil piles were identified as a significant risk for closure. 
The Mine Closure Plan (MCP), developed in conjunction with the South Australian Department for Energy and Mining, included requirements to: (a) identify spoil piles at the mine with the potential for spontaneous combustion, and (b) demonstrate the effectiveness of re-sloping and covering of the spoil pile batters to control spontaneous combustion in spoil piles.

The mechanisms that may contribute to the transport of oxygen to support combustion within a spoil pile are convection, advection and diffusion (Kuo \& Ritchie 1999). Diffusion is driven by partial pressure (or concentration) gradients, while convection and advection are driven by total pressure gradients, which can be established by temperature gradients or physical processes such as fluctuations in atmospheric pressure. The material property that controls diffusion is the oxygen diffusion coefficient and convection is controlled by the intrinsic permeability. The potential for spontaneous combustion is determined by a material's capacity to oxidise and release heat. Under conditions where the rate of heat production within a volume of the spoil pile is more than the rate of heat loss, the temperature will rise and support an increase in reaction rates. This positive feedback may lead to thermal runaway and spontaneous combustion (Nelson \& Chen 2007).

To identify spoil piles with material characteristics that indicate a potential to spontaneously combust and therefore would require mitigation, a site-wide material sampling and characterisation program was undertaken. Characteristics assessed included geology, composition, time since mining, and self-heating rating (Williams et al. 2019). A result of the investigation was the identification of 19 propensity categories that formed four risk groups: (i) inert, (ii) low, (iii) medium and (iv) high. Spoil piles containing materials classed as high risk were determined to require mitigation.

The MCP mitigation measures (Flinders Power 2018) to manage spontaneous combustion were based on a literature review, site operational experience, and technical advice from MWH Global (2017). Mitigation measures for spoil piles comprised three main activities:

1. Re-profiling to reduce the batter slope angle.

2. Covering the batter with a layer of inert material.

3. Protecting the cover layer from surface water runoff by installing bunds at the crests of the reprofiled batters.

Batter slope angles would be reduced from approximately 1:1.3 (V:H) to within the range of 1:4.5 to 1:5.0 $(\mathrm{V}: \mathrm{H})$ by incrementally pushing thin layers of waste from the crest towards the toe multiple times to achieve the final slope. The single layer of fine-grained, clay-rich material cover would have a minimum thickness of $1.2 \mathrm{~m}$ after placement and compaction. Re-sloping and cover placement would be undertaken using D10 bulldozers, and the final slopes of the batter and cover would be verified using sequenced digital terrain measurements and geo-referenced ortho-mosaic images generated by unmanned aerial vehicle surveys (Jones \& Franklin 2019).

\section{Field trial}

A field trial of the mitigation strategy was established in a spoil pile on the southern side of the main series void at the location shown in Figure 1. The objective of the field trial was to demonstrate that oxygen supply into the spoil pile would effectively be limited after re-sloping and covering of the batter so that spontaneous combustion would cease to occur. The spontaneous combustion mitigation methods in the trial region were the same as those proposed for the spoil piles to be managed using mitigation strategies. A batter region representative of a large portion of the batters classed as high risk and with a surface temperature of $63^{\circ} \mathrm{C}$, which was $42^{\circ} \mathrm{C}$ higher than the temperature of the surrounding surface, was selected as the field trial location. Spoil pile construction in the trial region, which was completed in 2008, was undertaken by end dumping and dozing in one lift, with the tip head advancing progressively from east to west, producing one $24 \mathrm{~m}$ high lift. 


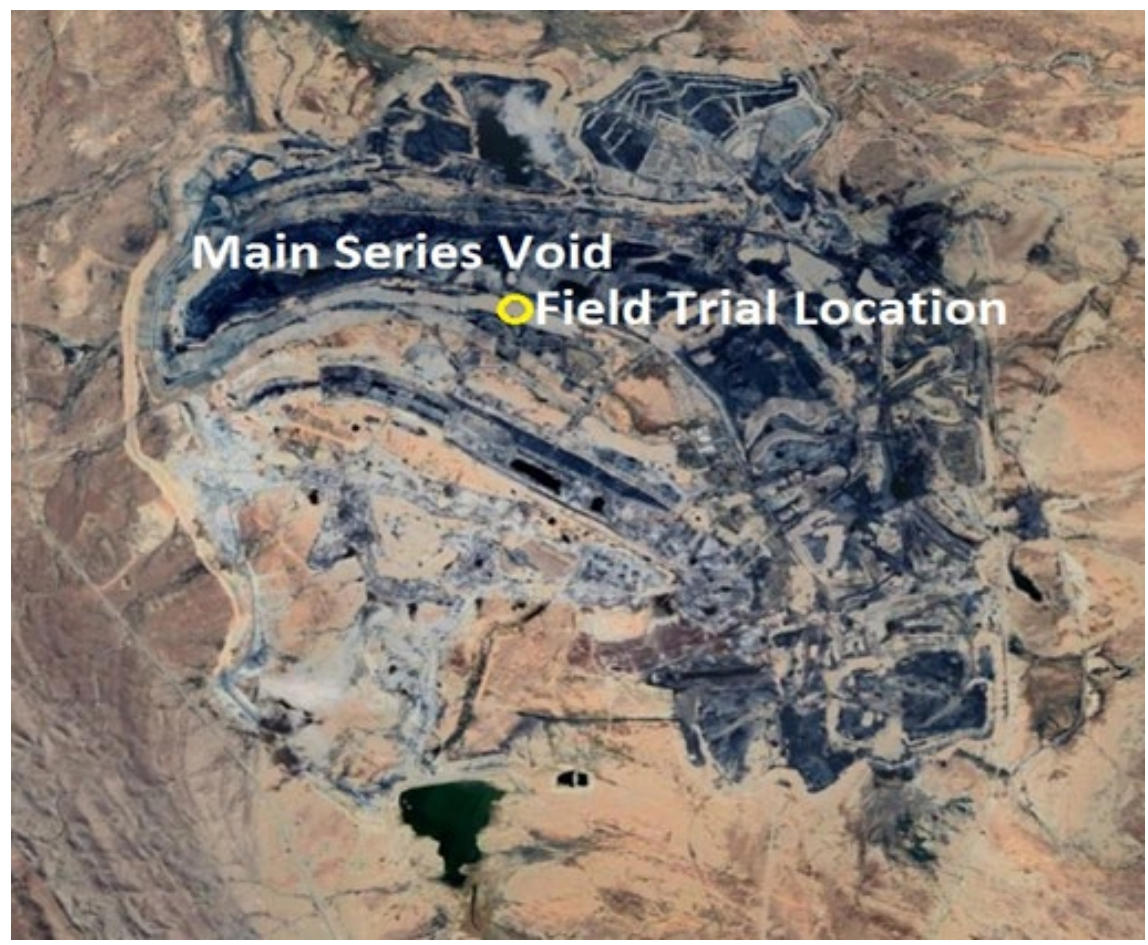

\section{Figure 1 Field trial location}

The high surface temperature distribution after re-profiling but before covering that influenced the selection of the field trial region is shown in the infrared image in Figure 2. The trial region was prepared according to the MCP mitigation measures described above. The minimum cover thickness was $1.2 \mathrm{~m}$. Potential high-risk hazards associated with the field trial installation identified in a risk assessment prior to site work included: (i) changed or contaminated atmosphere, (ii) surface collapse and (iii) high temperatures. Actions taken to ensure worker safety during drilling included surface temperature measurement and gas analysis and monitoring using personal low-volume multi-gas monitors.

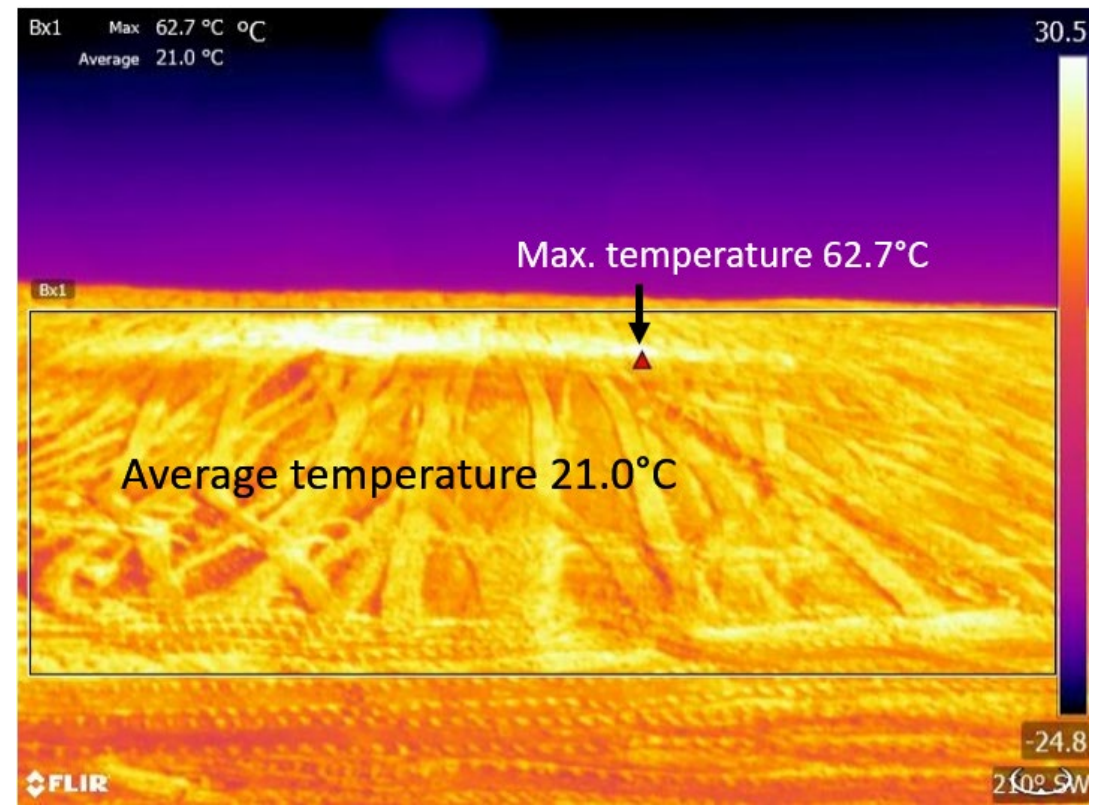

Figure 2 Surface temperature of the region selected as the field trial area 
A sonic drill rig was used to drill five holes in and behind the batter for sample collection and installation of monitoring equipment. (The sonic drill rig was selected because it required a small temporary access track, and because of its ability to drill in broken material and recover a relatively undisturbed core.) The locations of the drillholes are presented in Figure 3 (drillholes numbered H2, H3, H5, H6 and H9).

Drillcore was approximately $1 \mathrm{~m}$ long and the rock type, presence of coal, and temperature were logged. Each $1 \mathrm{~m}$ long sample interval was placed separately in a sealed container and subsequently frozen for future testing. Laboratory testing on selected samples was conducted to determine the potential of spoil pile material to combust. The samples were analysed for total sulfur and carbon content, moisture content (gravimetrically), and allowed to adiabatically self-heat to determine the potential to spontaneously combust under dry and moist conditions (R70 and incubation testing). The tests are described elsewhere (Garvie et al. 2019). Findings of that work showed that (i) coal had the potential for spontaneous combustion, as did rare siderite nodules containing pyrite; and (ii) carbonaceous mudstone had the capacity to combust in the presence of a heat source that raised its temperature above $100^{\circ} \mathrm{C}$.

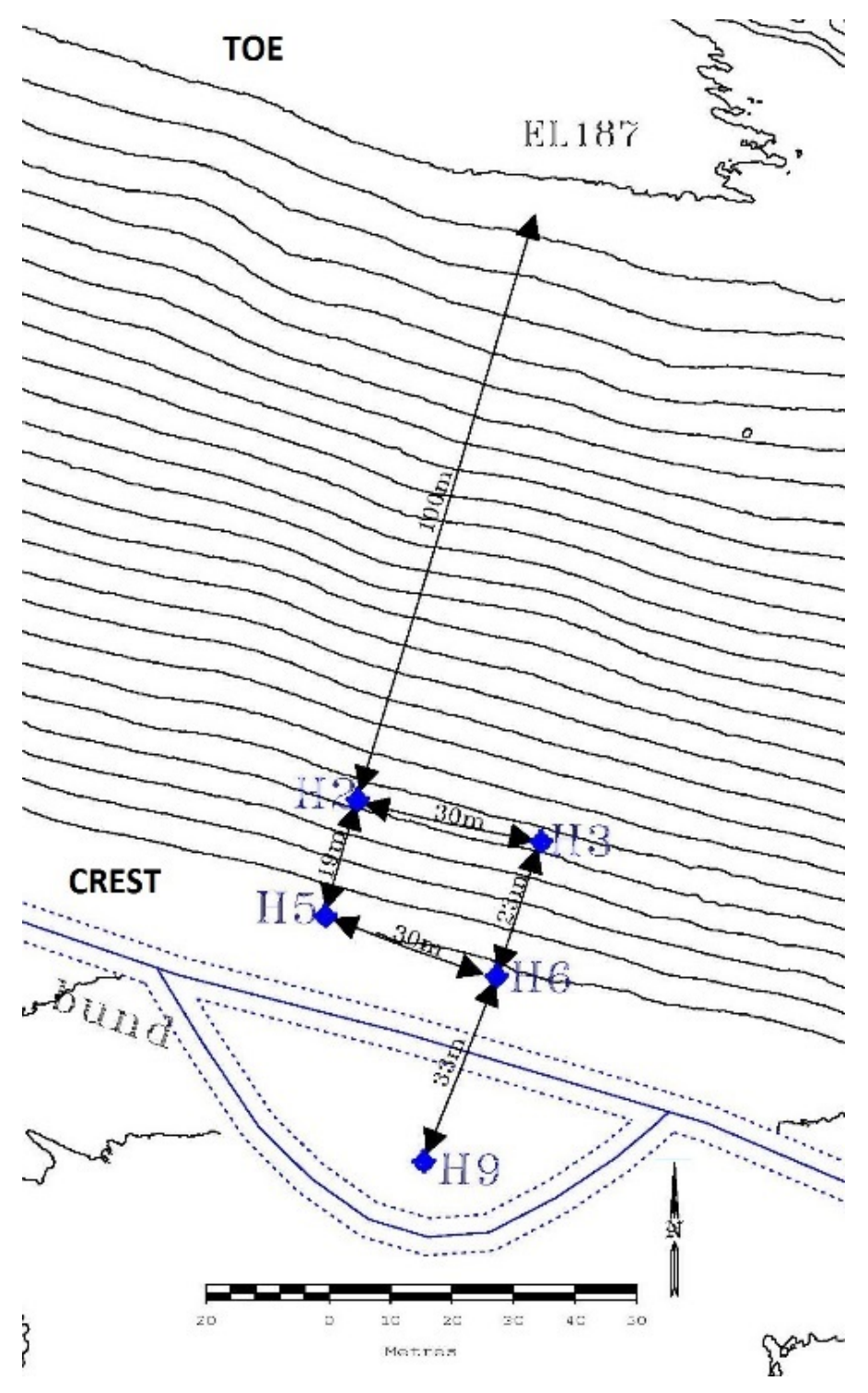

Figure 3 Monitoring locations in plan view 
Monitoring equipment was installed in the five vertical drill holes (Figure 4). Small diameter gas sampling tubes were installed to extend from the spoil pile surface and terminate at different depths within the spoil. The tubes were attached to a $45 \mathrm{~mm}$ diameter stainless steel pipe. A string of temperature sensors was hung inside the pipe. Oxygen and carbon dioxide concentrations were determined by pumping small volumes of pore gas from the spoil pile via the gas sampling tubes to portable gas analysers. Measurements were made multiple times in the week after instrument installation and then approximately monthly for the first 15 months and quarterly thereafter.

Immediately to the east of the drill holes, the dry bulk density and saturated hydraulic conductivity were measured at four depths in the cover and at three depths in the spoil to a maximum of $1.2 \mathrm{~m}$ below the spoil surface. Test pits were dug to access the measurement locations. The dry bulk density and saturated hydraulic conductivity were measured in situ with a densometer and falling head permeability test (Porchet method) respectively.

The oxygen diffusion coefficient was estimated from the gravimetric moisture content and bulk density data, and the intrinsic permeability was calculated from the saturated hydraulic conductivity.

Surface conditions will change in response to environmental factors such as rainfall. Assessment of how the surface may evolve and the potential for consequent changes within the spoil pile are outside the scope of the work reported here. Monitoring is planned for at least five years to provide a basis for forecasting long-term behaviour.

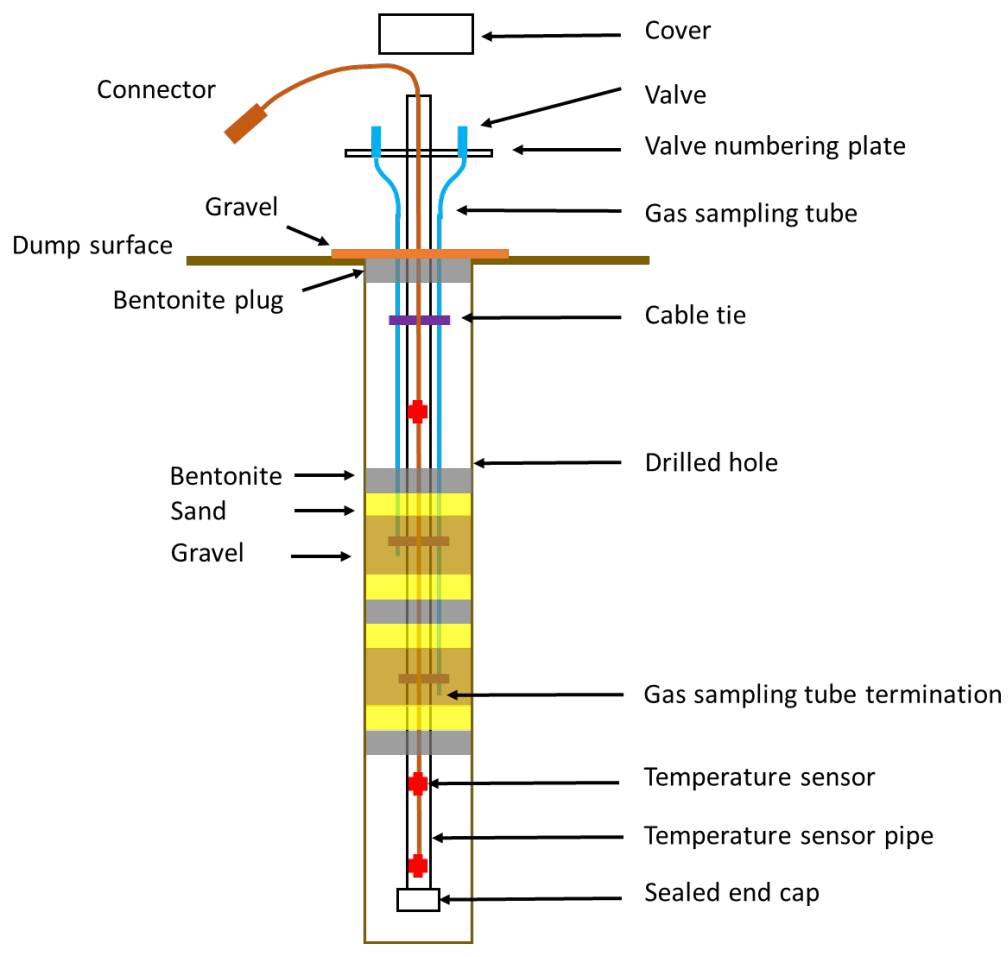

Figure 4 Schematic of monitoring equipment installation

\section{Results and interpretation}

\subsection{Rock type}

Almost all spoil material obtained from the trial area was identified as carbonaceous mudstone. Representative samples are presented in Figure 5 and Figure 6. Coal was identified in one drillhole only. This finding was consistent with a previous investigation that estimated coal made up approximately $0.8 \%$ of the spoil pile volume (CLD Mining 2018). 


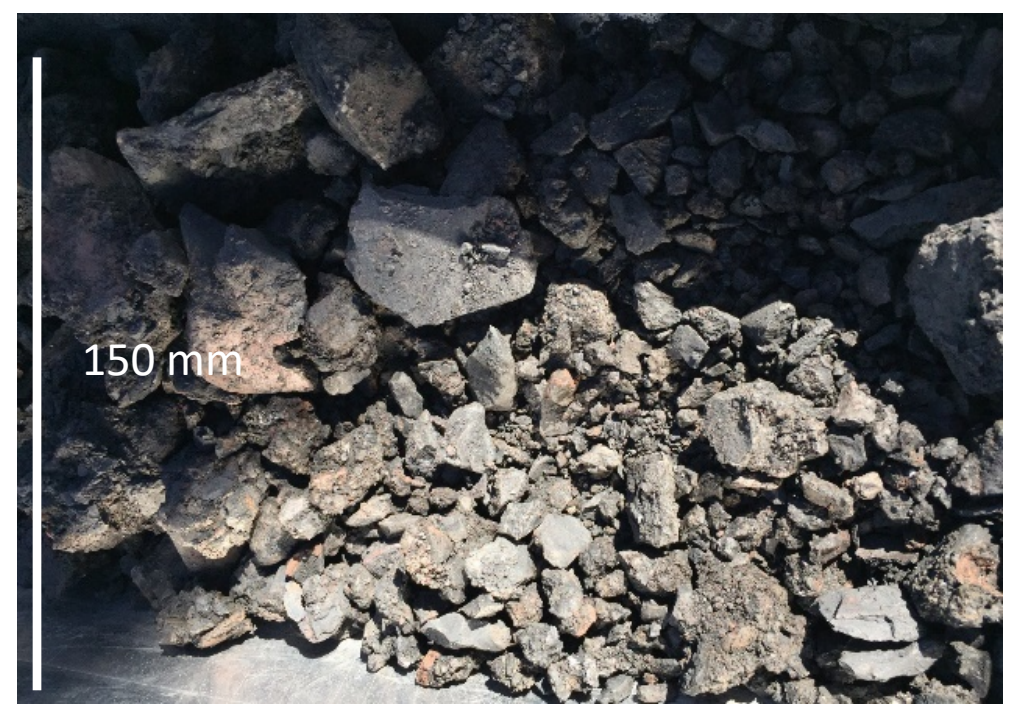

Figure 5 H6 carbonaceous mudstone core

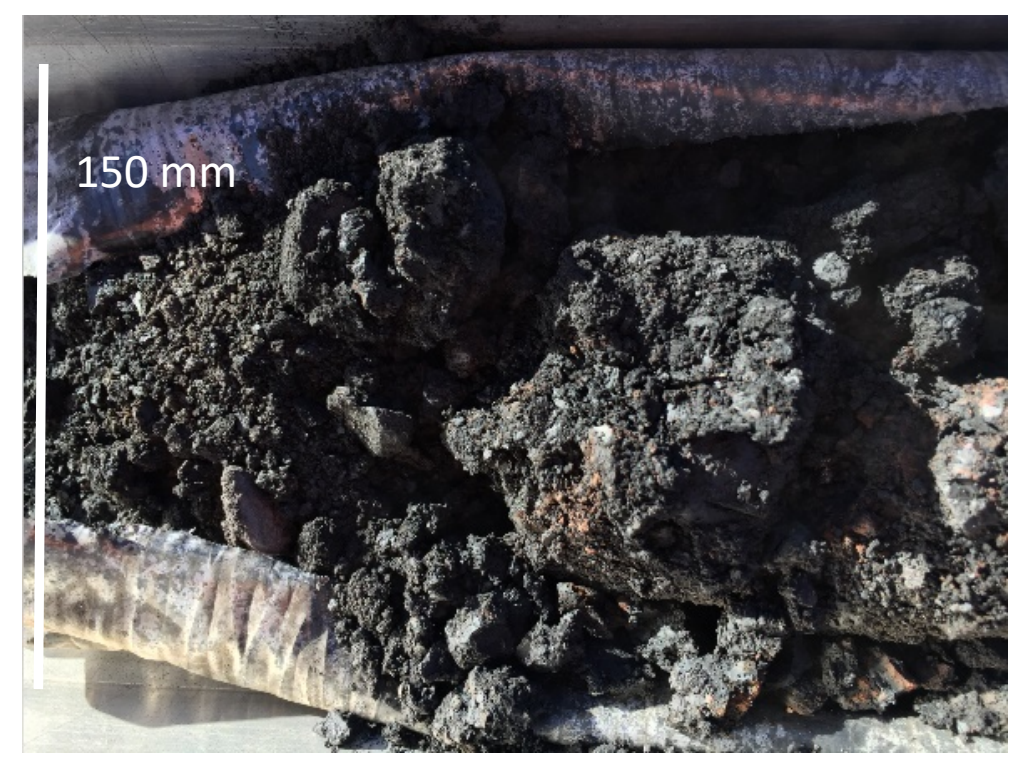

Figure 6 H9 carbonaceous mudstone core

\subsection{Dry bulk density and intrinsic permeability}

Measured dry bulk densities and intrinsic permeabilities are presented in Figure 7 for cover material and Figure 8 for the underlying spoil. Bulk densities in the cover material ranged between 1.34 and $1.65 \mathrm{t} / \mathrm{m}^{3}$ and those in the waste ranged between 1.24 and $1.57 \mathrm{t} / \mathrm{m}^{3}$. Intrinsic permeability values of the cover material and spoil were similar and ranged between $1 \times 10^{-14}$ and $1 \times 10^{-13} \mathrm{~m}^{2}$.

Intrinsic permeability values of cover material and waste rock measured at six other mines are presented in Table 1. The high values for the Questa, Schlema-Alberoda and Sullivan sites (i.e. $1 \times 10^{-9}$ to $1.1 \times 10^{-8} \mathrm{~m}^{2}$ ), also shown in the table, were required in the numerical modelling investigations of gas transport and sulfide mineral oxidation to develop convective and advective gas transport. This suggests that permeabilities less than $10^{-9} \mathrm{~m}^{2}$ may not support convection. Numerical modelling simulations by Pantelis \& Ritchie (1991) of a sulfide mineral bearing waste rock dump during the first four years after dump construction for dumps $20 \mathrm{~m}$ high indicated that convection would not be considered significant for intrinsic permeabilities below $10^{-10} \mathrm{~m}^{2}$. Although the oxidising material in the modelled dumps was not carbonaceous mudstone, and the intrinsic permeability more than $2.5 \mathrm{~m}$ below the surface of the field trial 
area was not quantified, the modelling results indicate that the low intrinsic permeability in the cover material and near-surface spoil could be expected to reduce the potential for convective gas transport.

Table 1 Intrinsic permeabilities determined for waste rock dumps

\begin{tabular}{lllll}
\hline Mine & \multicolumn{2}{l}{ Intrinsic permeability } & \multicolumn{2}{l}{ Reference } \\
& Minimum & Average & Maximum & \\
\hline Aitik & $2.6 \times 10^{-11}$ & - & $1.4 \times 10^{-9}$ & Ritchie (1994) \\
Antamina & $4 \times 10^{-11}$ & - & $2 \times 10^{9}$ & Vriens et al. (2018) \\
Diavik - Type I test pile & $4 \times 10^{-10}$ & $1.8 \times 10^{-9}$ & $3 \times 10^{-9}$ & Amos et al. (2015) \\
Diavik - Type III test pile & $2 \times 10^{-10}$ & $1.8 \times 10^{-9}$ & $4 \times 10^{-9}$ & Amos et al. (2015) \\
$\begin{array}{l}\text { Diavik-covered test pile - Type I } \\
\text { cover }\end{array}$ & $4 \times 10^{-10}$ & $1.4 \times 10^{-9}$ & $3 \times 10^{-9}$ & Amos et al. (2009) \\
Diavik-covered test pile - till cover & $1 \times 10^{-10}$ & $2.3 \times 10^{-10}$ & $4 \times 10^{-10}$ & Amos et al. (2015) \\
Heath Steele & $1.17 \times 10^{-10}$ & $2.9 \times 10^{-9}$ & $1.7 \times 10^{-8}$ & MEND (1997) \\
Kelian & $3.9 \times 10^{-13}$ & - & $9.3 \times 10^{-10}$ & Tan \& Ritchie (1997) \\
Questa & $1 \times 10^{-9}$ & - & $5 \times 10^{-8}$ & Lefebvre et al. (2002) \\
Rum Jungle & $8.9 \times 10^{-13}$ & - & $1.9 \times 10^{-9}$ & Kuo \& Ritchie (1999) \\
Schlema-Alberoda & - & $1.1 \times 10^{-8}$ & - & Lefebvre et al. (2016) \\
Sullivan (cover) & - & $5 \times 10^{-12}$ & - & Lahmira et al. (2014) \\
Sullivan (waste rock) & - & $5 \times 10^{-9}$ & - & Lahmira et al. (2014) \\
\hline
\end{tabular}

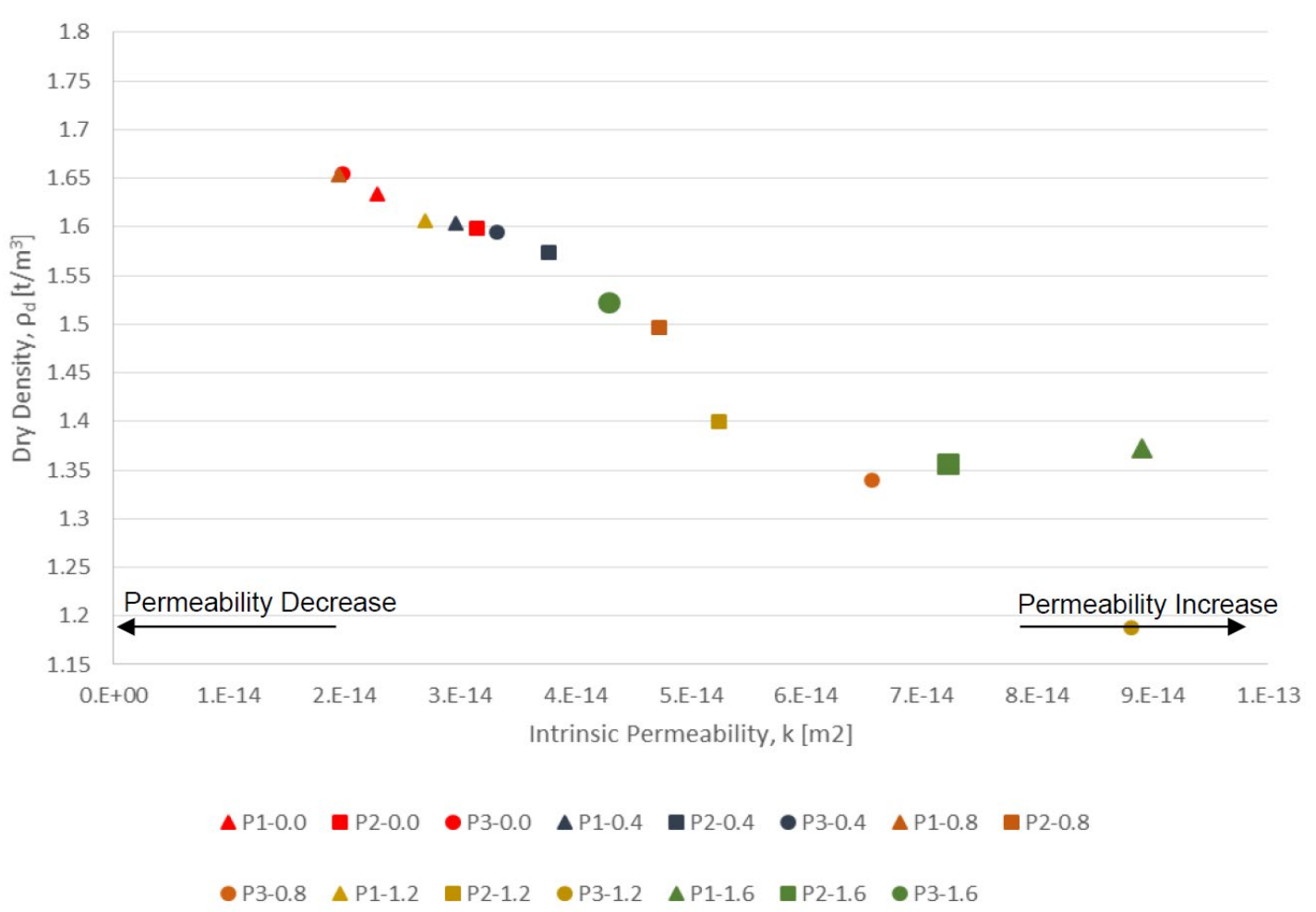

Figure 7 Cover material - field dry density and intrinsic permeability. Note: the coloured symbols represent different measurement locations. Source: Coffey (2017) 


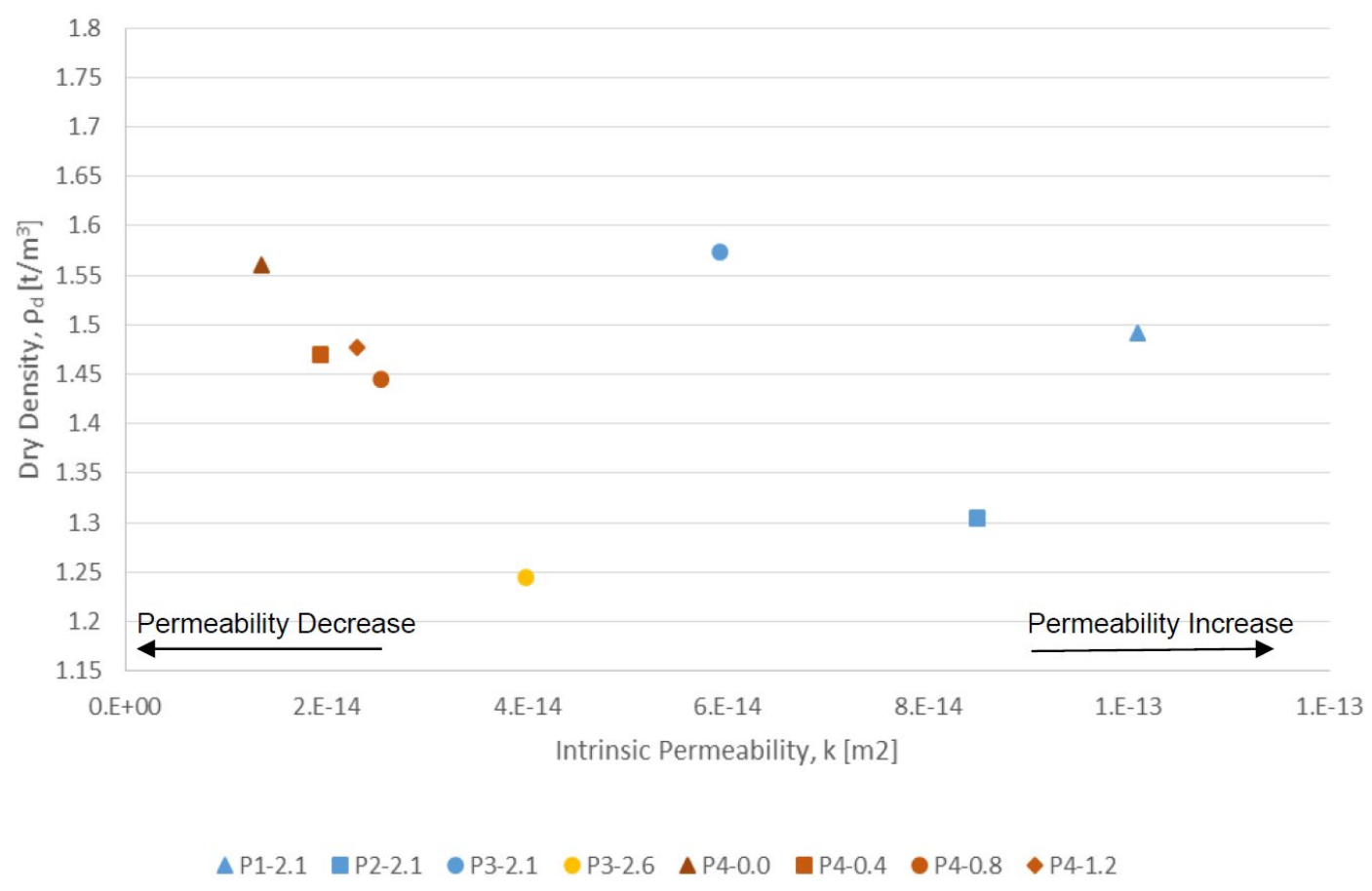

Figure 8 Spoil - field dry density and intrinsic permeability. Note: the coloured symbols represent different measurement locations. Source: Coffey (2017)

\subsection{Oxygen diffusion coefficient}

Ranges of the oxygen diffusion coefficients estimated from degrees of saturation calculated using measured field dry unit weight, specific gravity and the gravimetric water contents of samples and the relationship between the degree of saturation and oxygen diffusion coefficient provided by Aachib et al. (2004) are presented in Table 2.

Oxygen diffusion coefficients for waste rock reported by Ritchie (1994) for other mines are presented in Table 3. Median oxygen diffusion coefficient values of the trial were approximately one quarter to one third for those of waste rock. Ritchie (1995) showed, under simplifying assumptions, that the depth of oxygen diffusion below a surface in an oxidising material is proportional to the square root of the oxygen diffusion coefficient of the cover and oxygen-consuming waste. Using the model and an oxygen penetration depth of $1.5 \mathrm{~m}$ below the trial area cover, the oxygen consumption rate is estimated to be in the order of $1 \times 10^{-6} \mathrm{~kg}\left(\mathrm{O}_{2}\right) / \mathrm{m}^{3} / \mathrm{s}$. This rate is high compared to rates commonly determined for oxygen consumption in waste rock dumps due to sulfide mineral oxidation.

Table 2 Summary statistics for the degree of saturation and oxygen diffusion coefficients - Leigh Creek

\begin{tabular}{llllllll}
\hline & \multicolumn{3}{c}{ Degree of saturation (S) } & \multicolumn{3}{c}{$\mathrm{DO}_{2}\left(\mathrm{~m}^{2} / \mathrm{s}\right)$} \\
Material & Min & Average & Max & Min & Average & Max \\
\hline Cover & 0.31 & 0.49 & 0.69 & $4.0 \times 10^{-7}$ & $1.2 \times 10^{-6}$ & $1.9 \times 10^{-6}$ \\
Interface & 0.34 & 0.49 & 0.74 & $7.9 \times 10^{-7}$ & $1.5 \times 10^{-6}$ & $1.9 \times 10^{-6}$ \\
Spoil & 0.42 & 0.68 & 1.0 & $5.1 \times 10^{-7}$ & $1.1 \times 10^{-6}$ & $1.9 \times 10^{-6}$ \\
\hline
\end{tabular}

Note: the assumed specific gravities were $2.6 \mathrm{t} / \mathrm{m}^{3}$ for the cover and $2.5 \mathrm{t} / \mathrm{m}^{3}$ for the interface and spoil. 
Table 3 Measured in situ oxygen diffusion coefficients in spoil dump material - other mines (Ritchie 1994)

\begin{tabular}{lll}
\hline Mine and location & $\begin{array}{l}\text { Number of measurement } \\
\text { points in waste dump }\end{array}$ & $10^{6} \times \mathrm{DO}_{2}\left(\mathrm{~m}^{2} / \mathbf{s}\right)$ \\
\hline Aitik Mine, Sweden & 2 & $(2.25 \pm 1.04)-(6.85 \pm 1.02)$ \\
Heath Steele, Canada & 3 & $(2.65 \pm 0.55)-(3.35 \pm 0.25)$ \\
Woodlawn, Australia & 2 & $(3.49 \pm 1.64)-(5.07 \pm 0.39)$ \\
\hline
\end{tabular}

\subsection{Monitoring results: oxygen, carbon dioxide and temperature profiles}

Oxygen concentration and temperatures measured at $\mathrm{H} 6$ are presented at selected times in Figure 9 and Figure 10, respectively. In general, similar oxygen concentration and temperature trends have been observed at all five monitoring installations below the covered areas. The oxygen concentrations decreased rapidly below the cover (within $2 \mathrm{~m}$ ) and were near zero at greater depths. Based on the observed oxygen concentration profiles, oxidation rates would be very low at depths greater than $2 \mathrm{~m}$ from the spoil surface. This general form of the distribution indicates that oxygen transport is limited to diffusion (Ritchie 1995). Between July 2018 and March 2019 small increases in oxygen concentration (up to 2.5\%) were observed at depths greater than $2 \mathrm{~m}$ for three of the instrumented locations, indicating that changes in oxygen supply rates may have occurred. Further investigation is underway because the increases coincided with a change in gas analyser (original gas analyser was replaced with one able to measure carbon dioxide).

The temperatures at the beginning of the trial (June 2017) were non-uniform due to remnant heat from oxidation that had occurred prior to the trial region construction and peaked at depths of about $13 \mathrm{~m}$. The initial peak temperature at $\mathrm{H} 6$ was $137.5^{\circ} \mathrm{C}$, which is above the threshold temperature for thermal runaway $\left(100^{\circ} \mathrm{C}\right.$ ) as determined by previous laboratory studies (Garvie et al. 2019). From the time measurements first commenced, temperatures at depths greater than $3 \mathrm{~m}$ below the surface have been decreasing, which is evidence of reduced rates of oxidation and net heat loss.

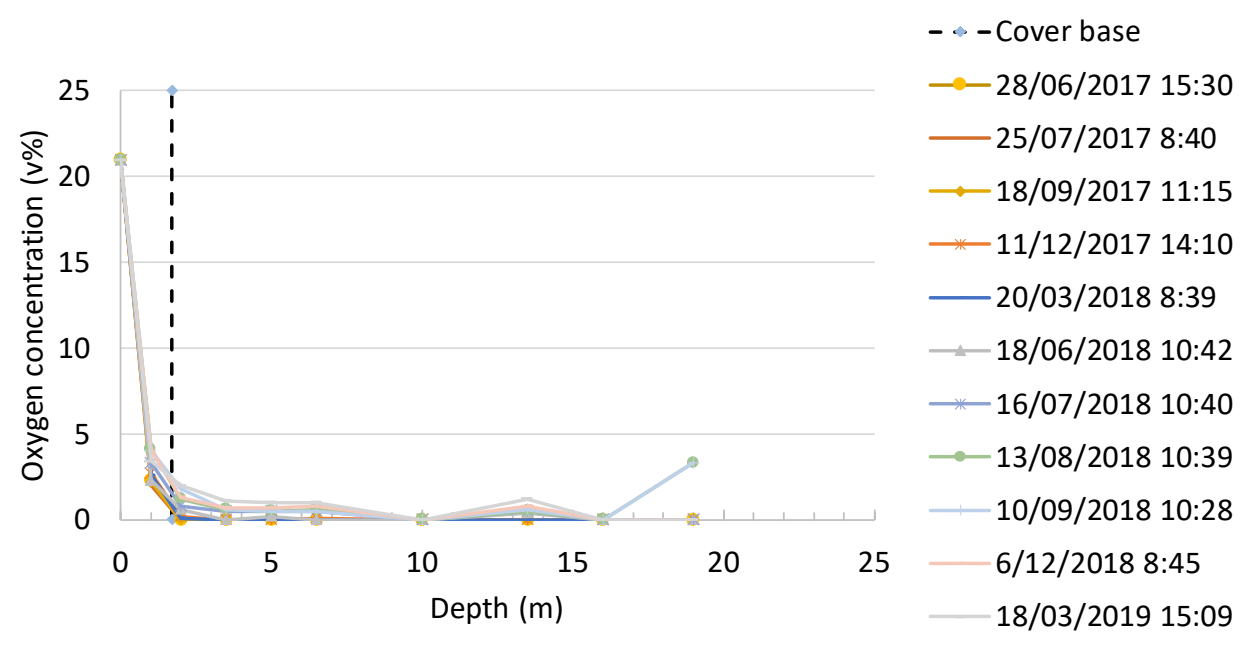

Figure 9 Oxygen concentrations at $\mathrm{H} 6$ 


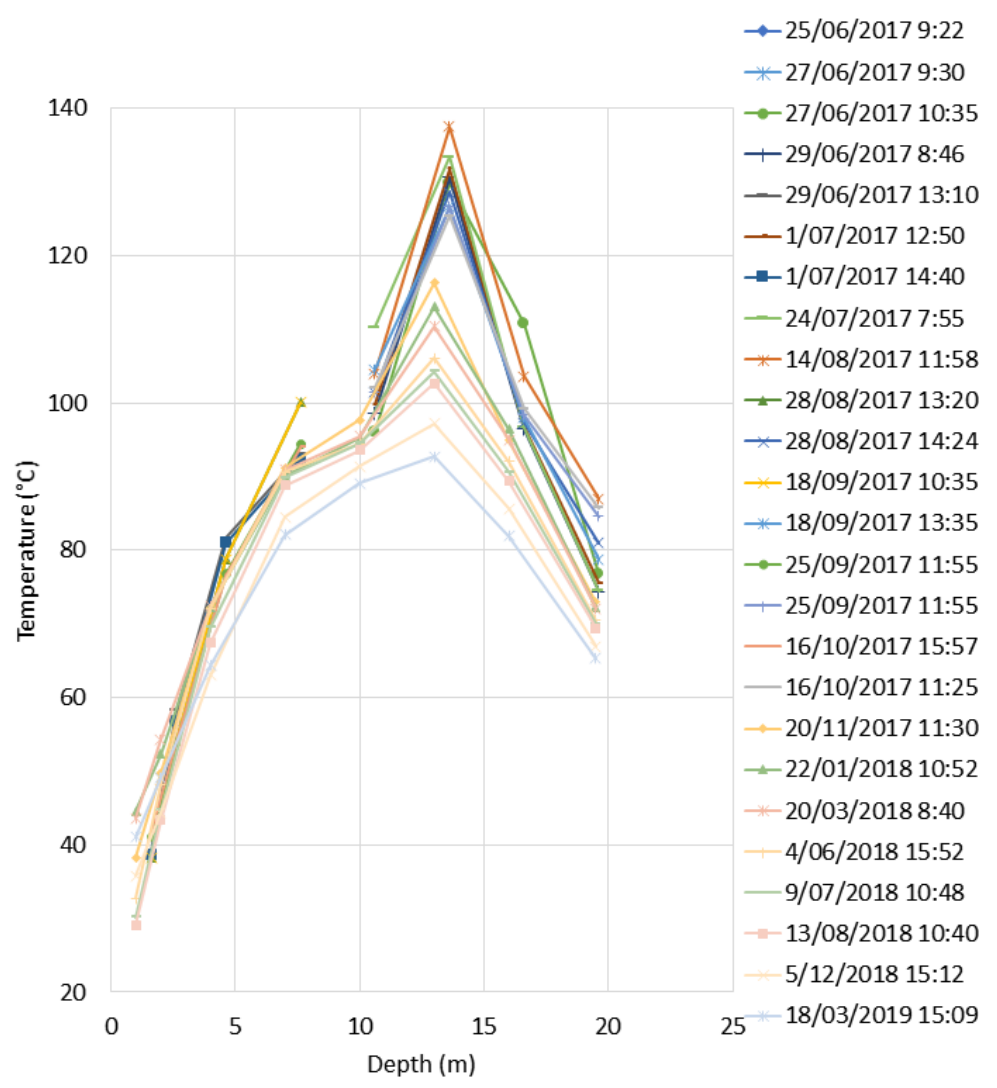

Figure 10 Temperature at $\mathrm{H} 6$

Figure 11 shows that maximum temperatures at each installation have decreased continuously and that all installations are below the threshold for thermal runaway. Temperature contour diagrams were constructed using temperatures measured along vertical lines of each measurement location in the $\mathrm{H} 3, \mathrm{H} 6$, H9 cross-section at two times. Figure 12 presents inferred temperature contours and heat conduction paths for that cross-section. The figure illustrates the temperature decrease and heat loss from the batter that has led to the peak temperature at $\mathrm{H} 6$ decreasing below $100^{\circ} \mathrm{C}$ in October 2018.

Carbon dioxide measurements commenced in July 2018. Figure 13 shows that $\mathrm{CO}_{2}$ concentrations at $\mathrm{H} 6$ rose steeply to about $31 \% \mathrm{CO}_{2}$ at a depth of about $2 \mathrm{~m}$ below the batter surface. The concentrations were relatively constant below that depth and, between July and September 2018, remained relatively constant over time. The shape of the profile is consistent with the oxidation of carbonaceous mudstone and the production of $\mathrm{CO}_{2}$ in the top $1 \mathrm{~m}$ of spoil, combined with no loss of $\mathrm{CO}_{2}$ through the base of the pile.

After September 2018 the concentrations below $2 \mathrm{~m}$ depth decreased uniformly in space and by about $6 \%$ $\mathrm{CO}_{2}$ by 18 March 2019. Similar changes were observed at other locations. This change in the $\mathrm{CO}_{2}$ profile is not consistent with the complete oxidation of carbonaceous waste in the top $1 \mathrm{~m}$ of spoil. Under such conditions, $\mathrm{O}_{2}$ would diffuse further into the waste and oxidise a layer of carbonaceous mudstone in the depth range of approximately 2-3 $\mathrm{m}$ from where $\mathrm{CO}_{2}$ would be generated. The $\mathrm{CO}_{2}$ concentration below the oxidising layer would remain the same. This is illustrated in Figure 14, which presents modelled $\mathrm{CO}_{2}$ concentrations, calculated by solving the gas transport equations for oxygen diffusion, oxygen consumption by the oxidation of carbonaceous mudstone and subsequent $\mathrm{CO}_{2}$ generation. While the depth of the layer of $\mathrm{CO}_{2}$ generation increases as the layer of oxidation shifts to greater depths, the $\mathrm{CO}_{2}$ concentration below the oxidising layer remains constant, which is in contrast to the measured concentrations. Although the recent changes in concentration are not consistent with a moving oxidation front, they are consistent with $\mathrm{CO}_{2}$ loss that is uniform below the $2 \mathrm{~m}$ depth. Further investigation is required to demonstrate that $\mathrm{CO}_{2}$ loss is occurring. 


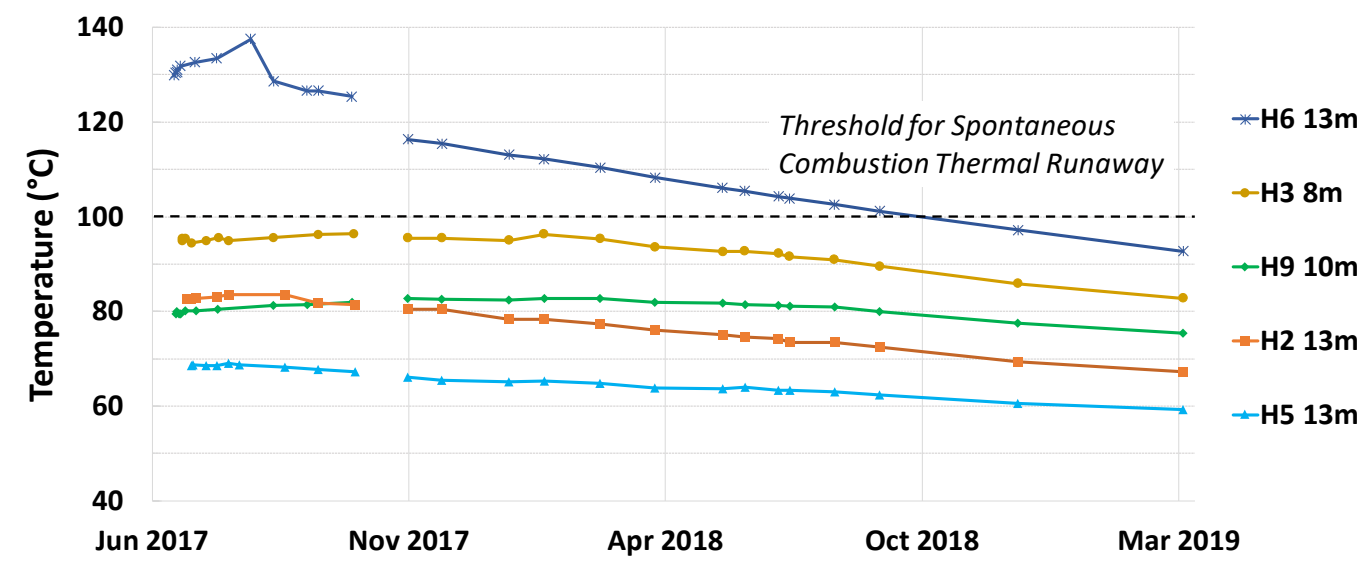

Figure 11 Maximum temperatures at each installation over time. Note that the gap in results in October 2017 is due to the change of temperature sensors
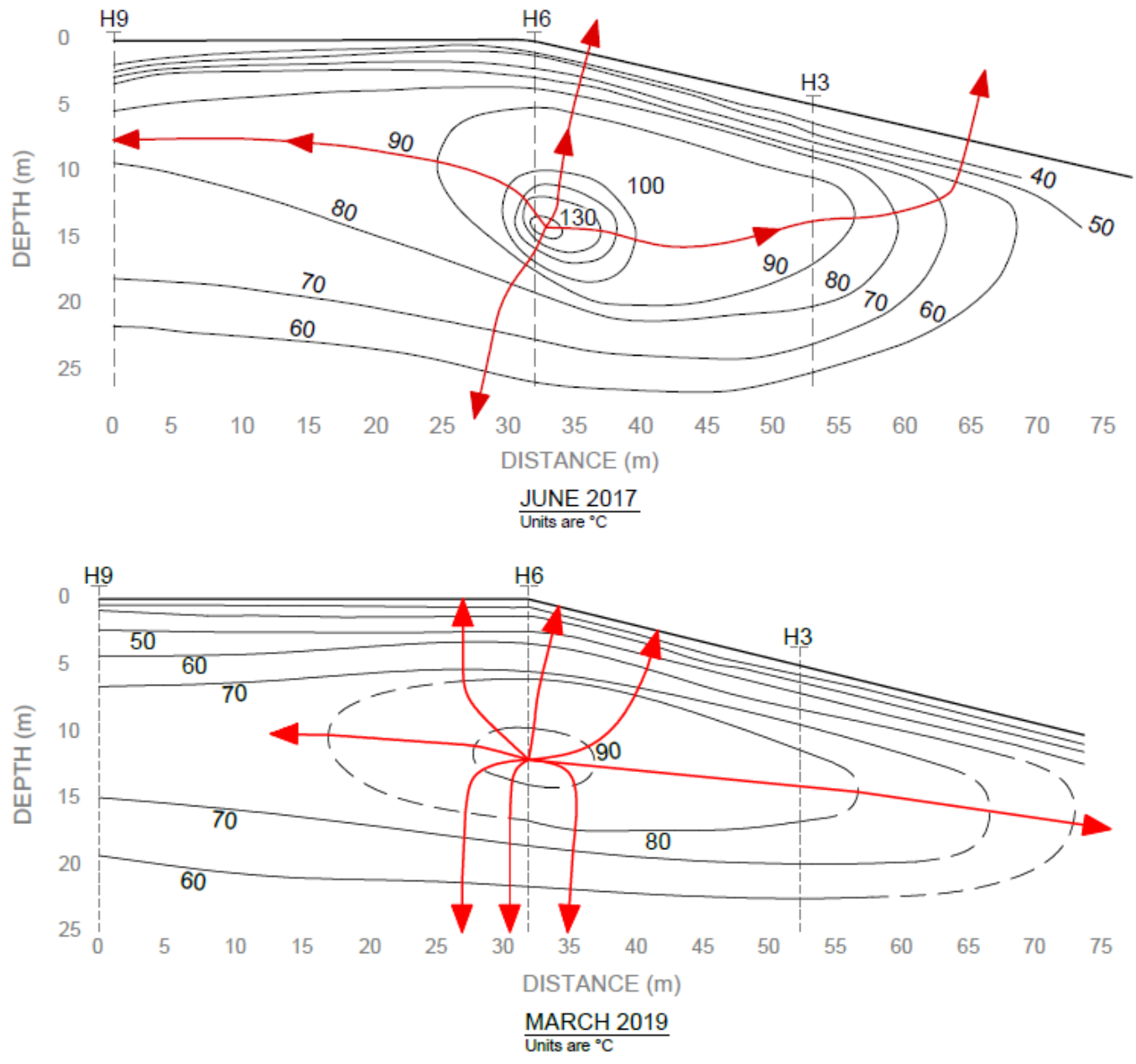

Figure 12 Inferred temperature contours and heat conduction pathways in the trial batter at $\mathrm{H} 6$ 


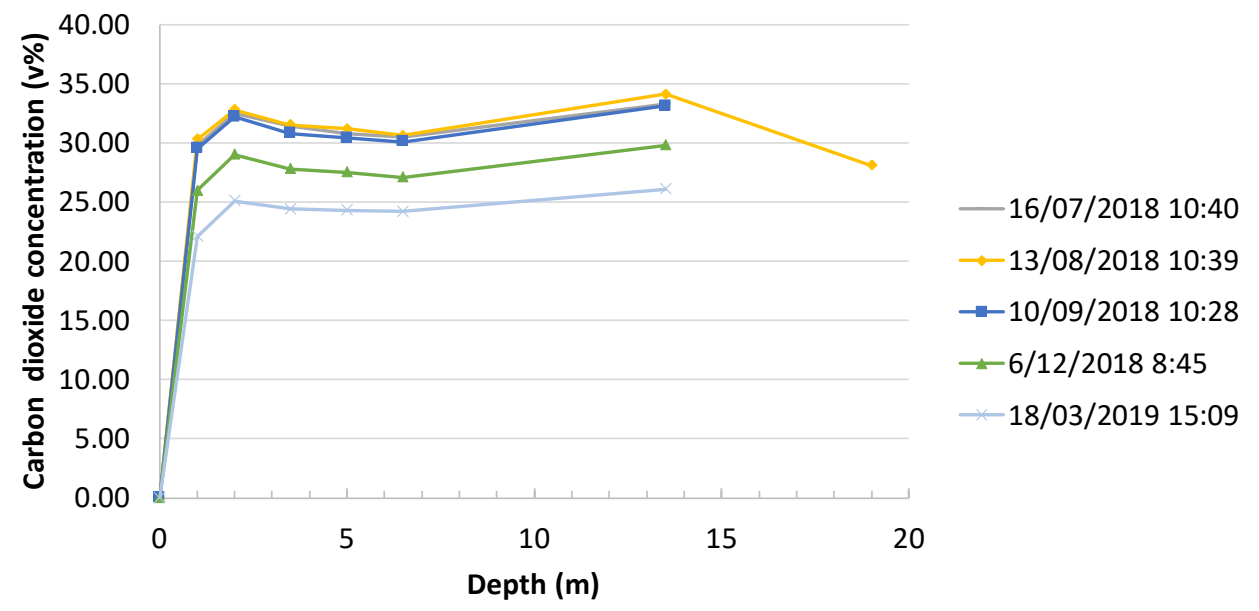

Figure 13 Carbon dioxide concentration at H6. Note that data of 16/07/2018 and 10/09/2018 are coincident

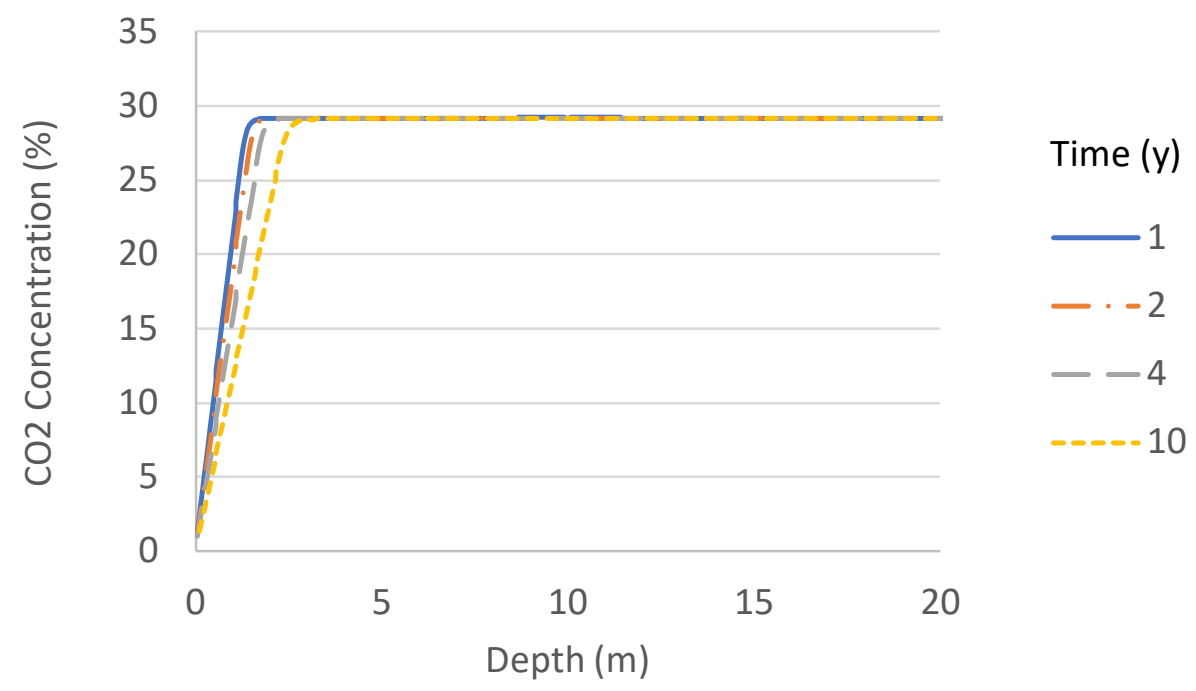

Figure 14 Modelled $\mathrm{CO}_{2}$ concentrations at one, two, four and 10 years

\section{$4 \quad$ Summary and conclusion}

Most spoil material in the trial region is carbonaceous mudstone, which of itself does not have the capacity to spontaneously combust, but may combust if heated by a separate heat source to above its thermal runaway threshold. Potential heat sources within the spoil pile are coal and pyrite (as contained in siderite nodules). Although both heat sources are rare and the second unlikely to be exposed to oxygen, spontaneous combustion occurred during mining operations.

Intrinsic permeabilities of the compacted cover material and the reprofiled (and trafficked) carbonaceous mudstone in the top $1.2 \mathrm{~m}$ of spoil ranged between $10^{-14}$ and $10^{-13} \mathrm{~m}^{2}$. These values are low compared to values considered necessary to support convection and advection. In this respect, the mitigation measures are considered to have reduced the rate of oxygen ingress to the spoil. Median values of the diffusion coefficient calculated for the cover material and the top $1.2 \mathrm{~m}$ of spoil were in the range between $0.98 \times 10^{-6}$ and $1.2 \times 10^{-6} \mathrm{~m}^{2} \mathrm{~s}^{-1}$. These values are similar to those measured in waste. Combined with the limited depth of oxygen penetration they indicate the oxygen consumption rate is in the order of $1 \times 10^{-6} \mathrm{~kg}\left(\mathrm{O}_{2}\right) / \mathrm{m}^{3} / \mathrm{s}$.

The near-zero oxygen concentration and decrease in temperatures over time at depths of more than $2 \mathrm{~m}$ indicate that the elevated maximum temperatures at depths of about $13 \mathrm{~m}$ were due to heating prior to re-profiling and cover placement. 
With the reduced rate of oxygen supply brought about by the mitigation measures, and without heating at lower depths, the spoil has cooled with time to a point where measured temperatures within the spoil are below the threshold temperature for thermal runaway of the carbonaceous mudstone $\left(100^{\circ} \mathrm{C}\right)$. It is therefore concluded that re-profiling and covering have significantly reduced the potential for thermal runaway and combustion of the carbonaceous mudstone.

\section{Acknowledgement}

Flinders Power acknowledges GeoSonic Drilling and B3 Mining Services for their contributions to planning, installation, sample logging and analysis related to the field trial. The work would not have been completed without their expertise.

\section{References}

Aachib, M, Bonimpa, M \& Aubertin, M 2004, 'Measurement and prediction of the oxygen diffusion coefficient in unsaturated media, with application to soil covers', Water, Air and Soil Pollution, vol. 156, pp. 163-193.

Amos, R, Blowes, D, Smith, L \& Sego, DC 2009, 'Measurement of wind induced pressure gradients in a waste rock pile', Vadose Zone Journal, vol. 8, pp. 953-962.

Amos, RT, Blowes DW, Bailey, BL, Sego, DC, Smith, L \& Ritchie, AIM 2015, 'Waste-rock hydrogeology and geochemistry', Applied Geochemistry, vol. 57, pp. 140-156.

CLD Mining 2018, 'Assessment of fugitive coal in waste dumps', in Flinders Power 2018, Approved Mine Closure Plan, Appendix JJJ.

Coffey 2017, 'Geotechnical field test and discussion for the capping at field trial location - Leigh Creek mine closure', in Flinders Power 2018, Approved Mine Closure Plan, Appendix VV.

Flinders Power 2018, Approved Mine Closure Plan, April 2019, http://www.energymining.sa.gov.au/minerals/mining/mines_and_ quarries/leigh_creek_coal_mine, viewed 29

Garvie, A, Donaldson, K, Beamish, B, Williams, B \& Chapman, J 2019, 'Management of spontaneous combustion in coal overburden spoil piles', in N Aziz \& B Kininmonth (eds), Proceedings of the 2019 Coal Operators' Conference, University of Wollongong, Wollongong, pp. 265-273.

Jones, PL \& Franklin, C 2019, 'Relinquishment criteria verification: quality assurance/quality control using unmanned aerial vehicles', in AB Fourie \& M Tibbett (eds), Proceedings of the 13th International Conference on Mine Closure, Australian Centre for Geomechanics, Perth, pp. 1461-1476.

Kuo, E \& Ritchie, AIM 1999, 'Enhance oxidation by Cconvection in sulfidic rock piles: the influence of the form of the sulfidic oxidation rate', in RR Fernández (ed.), Mine, Water and Environment: Proceedings of the IMWA International Congress, International Mine Water Association, pp. 455-460.

Lahmira, B, Lefebvre, R, Hockley, D \& Phillip, M 2014, 'Atmospheric controls on gas flow directions in a waste rock dump', Vadose Zone Journal, vol. 13, no. 10.

Lefebvre, R, Lahmira, B \& Lobner, W 2016, 'Atmospheric control of radon emissions from a waste rock dump', Environmental Geotechnics, Paper 15.00066, Institute of Engineers.

Lefebvre, R, Lamontagne, A, Wels, C \& Robertson, A 2002, 'ARD production and water vapour transport at the Questa Mine', Proceedings of the Ninth International Conference on Tailings and Mine Waste, A.A. Balkema, Rotterdam, pp. 479-488.

MEND 1997, Assessment of Gas Transfer - ANSTO Model at Heath Steele Mines, MEND Project 1.22.1b, viewed 1 August 2019, http://mend-nedem.org/wp-content/uploads/1221B.pdf

MWH Global 2017, 'Leigh Creek coalfield spontaneous combustion management of waste rock dumps', in Flinders Power 2018, Approved Mine Closure Plan, Appendix AAA.

Nelson, MI \& Chen, XD 2007, 'Survey on the experimental work on self heating and spontaneous combustion of coal', The Geological Society of America, Reviews in Engineering Geology, vol. XVIII, pp. 21-83.

Pantelis, G \& Ritchie, AIM 1991, 'Macroscopic transport mechanisms as a rate-limiting factor in dump leaching of pyrite ores', Applied Mathematical Modelling, vol. 15, pp. 136-143

Ritchie, AIM 1994, 'Sulfide oxidation mechanisms: controls and rates of oxygen transport', in A JL Jambor \& DW Blowes (eds), Short Course on Environmental Geochemistry of SULFIDE Mine-Wastes, Waterloo, May.

Ritchie, AIM 1995, 'Application of oxidation rates in rehabilitation design', in NJ Grundon \& LC Bell (eds), Proceedings of the Second Australian Acid Mine Drainage Workshop, Minerals Council of Australia and Australian Centre for Minesite Rehabilitation Research, pp. 101-116.

Tan, Y \& Ritchie, AIM 1997, 'In-situ determination of thermal conductivity of waste rock material', Water, Air, Soil Pollution, vol. 98 , pp. 345-359.

Vriens, B, St. Arnault, M, Laurenzie, L, Smith, Leslie, Mayer, KU \& Beckie, RD 2018, 'Localised sulfide oxidation limited by oxygen supply in a full-scale waste rock pile', Vadose Zone Journal, vol. 17, no. 1, https://doi.org/10.2136/vzj2018.06.0119

Williams, B, Donaldson, K \& B Beamish 2019, 'Risk profiling and control of spontaneous combustion for coal mine closure', in AB Fourie \& M Tibbett (eds), Proceedings of the 13th International Conference on Mine Closure, Australian Centre for Geomechanics, pp. 563-576. 
